\title{
Fully Textile-Integrated Microstrip-Fed Slot Antenna for Dedicated Short-Range Communications
}

\author{
Leticia Alonso-González, Student, IEEE, Samuel Ver-Hoeye, Member, IEEE, Miguel Fernández-García, \\ Yuri Álvarez-López, Senior, IEEE, Carlos Vázquez-Antuña, Fernando Las-Heras Andrés, Senior, IEEE
}

\begin{abstract}
A novel fully textile-integrated antenna based on a slotted short-circuited microstrip line has been designed, manufactured and experimentally validated for its use in automobile upholsteries for dedicated short-range communications. The antenna can be manufactured using an industrial loom and a laser prototyping machine, avoiding subsequent treatments, sewing procedures or coatings. The manufactured antenna presents a central working frequency of $5.9 \mathrm{GHz}$ and a $9.3 \%$ bandwith. Good agreement between simulations and measurements has been achieved.
\end{abstract}

Index Terms-Antenna, dedicated short-range communications (DSRC), microwave, textile, textile-integrated antenna.

\section{INTRODUCTION}

D URING the last few years, there has been an increasing interest in flexible circuits, specially antennas, based on textile technology, thanks to the possibility of integrating them in special garments and automobile upholsteries, or developing comformable structures for biomedical applications. In the literature, a variety of solutions to develop Textile Integrated Circuits (TIC) has been proposed. Embroidered techniques [1]-[5], non-woven solutions [6]-[8], designs based on using several fabrics with different electromagnetic behaviour [9][11] or inkjet printed patterns over textile substrates [12]-[15] are some of the most cited solutions. More recently, there has been an increasing interest in the development of TIC based on Substrate Integrated Waveguide (SIW) technology [16], [17].

The before mentioned techniques used for the development of TIC, which have been described in [18], are conceived as a post treatment of existing fabrics by the use of different techniques such as adhesives, coatings or sewing procedures. These techniques cannot be performed in the fabric manufacture process, leading to a circuit which is not fully integrated into the textile. For these reasons, the mentioned solutions for developing TIC are not the best options for large scale production with existing industrial textile machinery, such as conventional looms with a dobby or jacquard weaving mechanism.

With the aim of pushing textile components to microwave frequencies, a technique based on the weaving technology,

This work has been supported by Gobierno de España TEC2015-72110EXP, TEC2016-80815-P and FPU14/00016 grant, and by the Gobierno del Principado de Asturias (PCTI)/FEDER-FSE under projects IDI/2016/000372 and IDI/2017/000083.

The authors are with the Signal Theory and Communications Area at the University of Oviedo, Gijón, E-33203 Spain (e-mail: lalonso@tsc.uniovi.es alonsoleticia@uniovi.es). which has already been discussed in [18] is applied to the development of a microwave fully integrated slotted microstrip antenna, for dedicated short-range communications (DSRC). This technique enables the integration of the final textile components in the fabric manufacturing process, without requiring subsequent treatments, making it suitable for large scale production. A microstrip geometry has been chosen which can be translated into a fully woven prototype, consequently, other types of antennas based on certain geometries such as circularshaped patches or coplanar-waveguide fed antennas have been dismissed.

A methodology to design and simulate TIC working in a range of frequencies in which the dimensions of the involved threads are comparable to the wavelength has been used in this paper. This methodology, which is based on a three-step parametric modelling, reduces the computational complexity of the inicial problem by defining several electromagnetically equivalent simpler problems and has already been thoroughly discussed in [19].

The paper is organised as follows, in Section II, the modelling technique used to simplify the simulations will be described. In section III, the employed materials will be characterised. In Section IV, the design of the woven antenna will be presented. In Section V, the fabrication process of the manufactured antenna will be explained. In Section VI, experimental validation will be presented and discussed.

\section{Description of The Modelling TeChNiQue}

A textile structure can be divided into its composing threads, the warp threads and the weft threads, which are perpendicular to each other. The warp direction coincides with the length of the fabric, whereas the weft direction coincides with the width of the fabric and, consequently, with the width of the loom.

In addition, each of the threads is composed of a number of individual filaments, whose material properties are known. Therefore, the electromagnetic simulation of a microwave TIC constitutes a complex computational problem, due to the highdensity mesh required to accurately model the multifilament structure. For this reason, a modelling based on the three steps defined in Fig. 1 and described in [19] has been applied to develop a fully textile-integrated microstrip-fed slot antenna.

\section{CHARACTERISATION OF THE EMPLOYED MATERIALS}

Different materials have been employed for the design of the antenna. In this section they are characterised using the 


\begin{tabular}{|c|c|c|c|c|}
\hline \multirow{2}{*}{\multicolumn{2}{|c|}{$\begin{array}{c}\text { FILAMENT MODEL } \\
\varepsilon_{\mathrm{fil}} \quad \tan (\delta)_{\mathrm{fil}}\end{array}$}} & \multicolumn{2}{|c|}{ MONOF. MODEL } & LAYERS MODEL \\
\hline & & $\varepsilon_{\mathrm{mon}}$ & $(\delta)_{\mathrm{mon}}$ & $\varepsilon_{\mathrm{eq}}$ \\
\hline 4 & v & $\pi$ & v & 4 \\
\hline $\begin{array}{l}\text { Cross } \\
\text { section }\end{array}$ & $\begin{array}{l}\text { Linear } \\
\text { Density }\end{array}$ & $\begin{array}{l}\text { density } \\
\text { naterials }\end{array}$ & $\begin{array}{r}\text { Densit } \\
(e f\end{array}$ & $\begin{array}{l}\text { weave } \\
\text { pi) }\end{array}$ \\
\hline
\end{tabular}

Fig. 1. Three-step characterisation model, corresponding relative permittivities and loss tangents and required parameters for translation between filament model (FM), monofilament model (MM) and layers model (LM).

modelling procedure referenced in Section II. The design of the antenna will then be explained in detail in Section IV.

\section{A. Characterisation of the Electrically Conductive Materials}

Electrically conductive Shieldex 117f17 2-ply yarns with a resistance of $3.9 \Omega / \mathrm{cm}$ have been used for the weft threads. The ply number means the number of initial threads that are twisted around one another to create a single and stronger thread. These threads consist of two plies and each ply is formed by 17 filaments and weighs 117 dtex. These threads adopt the Pierce's elliptic cross section when they are in the woven structure. A single conductive Shieldex 117f17 1-ply warp yarn has also been used for the design of the antenna with a resistance of $7.8 \Omega / \mathrm{cm}$. This thread has been modelled keeping the circular-shaped cross section. The cross section approaches and correspondig dimensions of the different conductive threads are summarised in Table I, where the threads Shieldex 117f17 2-ply and Shieldex 117f17 1-ply have been denoted $S h x 2 p$ and Shxlp respectively for simplification.

Shieldex yarns are silver plated non-conductive threads which are manufactured from polyamide plastic (nylon). First, the nylon yarns are knitted into a fabric and plated with pure silver by an electrolysis process and then, the fabric is deknitted. Consequently, it can be guaranteed that every yarn is completely plated with $T_{\mathrm{c}}=0.5 \mu \mathrm{m}$ of silver.

Conductive $\operatorname{Sh} x 2 p$ yarns are composed of 2 plies of 17 filaments respectively, leading to $N_{\text {fils }}=34$ filaments, and each filament has a diameter of $D_{\mathrm{f}}=31 \mu \mathrm{m}$ as depicted in Fig. 2. As the diameter of each filament is $D_{\mathrm{f}}$ and the thickness of the coating is $T_{\mathrm{c}}$, then the diameter of the polyamide plastic core of each filament is $D_{\mathrm{f}}-T_{\mathrm{c}}=30.5 \mu \mathrm{m}$, as depicted in Fig. $3 \mathrm{a}$. The total surface of conductive coating in the 34 filaments cross section can be calculated using (1) and denoted by $S_{\mathrm{c} 2}$.

$$
S_{\mathrm{c} 2}=N_{\mathrm{fils}} \pi\left(\left(\frac{D_{\mathrm{f}}}{2}\right)^{2}-\left(\frac{D_{\mathrm{f}}-T_{\mathrm{c}}}{2}\right)^{2}\right)
$$

The total surface of conductive coating, $S_{\mathrm{c} 2}$, can be translated into an equivalent conductive ring whose thickness is given by $T_{\mathrm{R} 2}$, as depicted in Fig. 3a. It is calculated using (2), being $R_{\mathrm{HS}}$ and $R_{\mathrm{VS}}$ the horizontal and vertical semi-axis of the Sh $x p$ cross section, respectively, as summarised in Table I. The value of $T_{R}$ has been found to be $1.3497 \mu \mathrm{m}$.

$$
\pi R_{\mathrm{HS}} R_{\mathrm{VS}}-\pi\left(R_{\mathrm{HS}}-T_{\mathrm{R} 2}\right)\left(R_{\mathrm{VS}}-T_{\mathrm{R} 2}\right)=S_{\mathrm{c} 2}
$$

From the expression in (3), where $\delta_{\mathrm{Sd}}$ is the skin effect depth, $\rho_{\text {Silver }}=1.59 \times 10^{-8}(\Omega \mathrm{m})$ is the silver resistivity, $f$ is the operating frequency and $\mu$ is the electrically permeability,

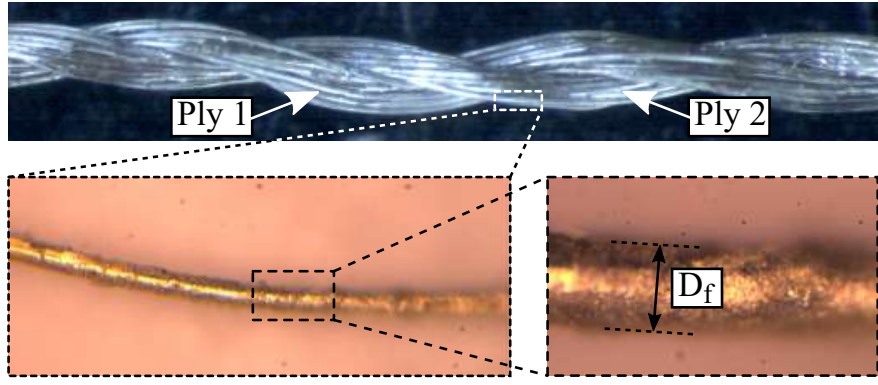

Fig. 2. Conductive Shieldex $117 f 17$ 2-ply thread and magnifications of one filament.

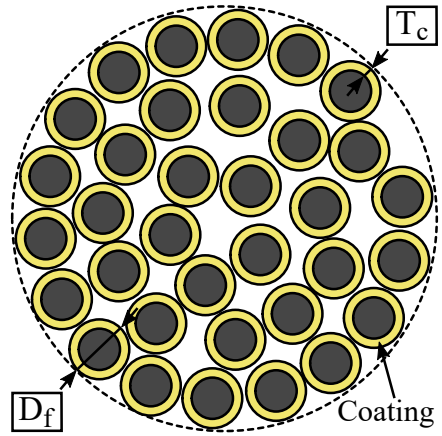

(a)

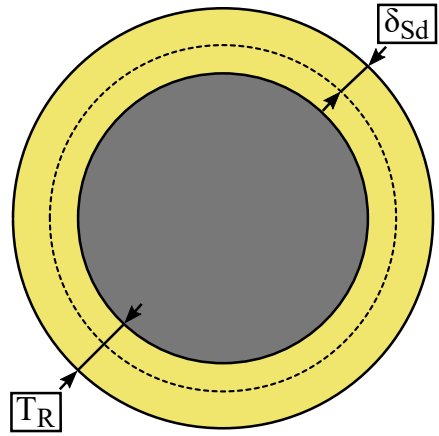

(b)
Fig. 3. Schematic drawing of the skin depth effect. (a) Cross section of a non-deformed $S h x 2 p$ thread. (b) Equivalent cross section of a non-deformed Sh $x 2 p$ thread.

the skin effect depth can be calculated as $\delta_{\mathrm{Sd}}=0.8252$ $\mu \mathrm{m}$. Due to the fact that the skin effect depth is smaller than the thickness of the equivalent silver coating, $T_{\mathrm{R} 2}$, the coated threads can be approximated by completely conductive threads.

$$
\delta_{\mathrm{Sd}}=\sqrt{\frac{\rho_{\text {Silver }}}{\pi f \mu}}
$$

The same procedure has been used for the Shxlp thread which is composed of one ply, threfore, $N_{\text {fils }}=17$ threads, leading to another equivalent ring whose thickness is given by $T_{\mathrm{R} 1}=7.4440 \mu \mathrm{m}$. Consequently, the Shxlp thread can also be approximated by a completely conductive thread.

According to the procedure referenced in Section II, the conductivities of the monofilaments are $\sigma_{\mathrm{Shx} 2 \mathrm{p}}=2.72 \times 10^{5}$ $\mathrm{S} / \mathrm{m}$ and $\sigma_{\text {Shx } 1 \mathrm{p}}=2.61 \times 10^{6} \mathrm{~S} / \mathrm{m}$, respectively. Then, according to the same procedure and the design of the woven patterns which will be described in Section IV, the equivalent conductivity is given by $\sigma_{\mathrm{eq}}=4.8 \times 10^{3} \mathrm{~S} / \mathrm{m}$. This low value of $\sigma_{\mathrm{eq}}$ is due to the fact that, in the woven design, there are not conductive threads in the warp direction to form the ground plane.

\section{B. Characterisation of the Dielectric Materials}

For the dielectric parts of the antenna, three different types of threads have been used. For the weft threads, black polyethylene-terephthalate (commonly known as PET or polyester) 1670 dtex and uncoated PET 1530 dtex have 
TABLE I

Dimensions of the Cross Sections of the Conductive Materials

\begin{tabular}{ccccc}
\hline Thread & $\begin{array}{c}\text { Thread } \\
\text { direction }\end{array}$ & $\begin{array}{c}\text { Cross } \\
\text { section }\end{array}$ & Dimension & $\begin{array}{c}\text { Value } \\
(\mathrm{mm})\end{array}$ \\
\hline \hline Shxlp & Warp & Circular & Radius & 0.0125 \\
\hline \multirow{2}{*}{ Shx $x p$} & \multirow{2}{*}{ Weft } & Pierce & Horizontal semi-axis & 0.1 \\
\cline { 4 - 5 } & & & Vertical semi-axis & 0.03 \\
\hline
\end{tabular}

TABLE II

Characteristic Parameters of the Dielectric Materials

\begin{tabular}{lcc}
\hline \multicolumn{1}{c}{ Parameter } & PET & PES \\
\hline \hline Relative permittivity & $\varepsilon_{\text {fil_PET }}=3.7$ & $\varepsilon_{\text {fil_PES }}=3.4$ \\
\hline Loss tangent & $\tan (\delta)_{\text {fil_PET }}=0.001$ & $\tan (\delta)_{\text {fil_PES }}=0.01$ \\
\hline Density $\left(\mathrm{g} / \mathrm{cm}^{3}\right)$ & $\delta_{\text {fil_PET }}=1.5$ & $\delta_{\text {fil_PES }}=1.5$ \\
\hline
\end{tabular}

been used. For the warp threads, high tenacity polyethersulfone (commonly known as PES) 550 dtex has been used. The characteristic parameters of the employed materials are summarised in Table II [21], [22].

For the PES warp yarns (denoted by $P E S_{\text {warp }}$ ), the circular cross section has been kept due to their high tenacity. For the uncoated or white PET weft threads (denoted by $P E T_{\text {weft_w }}$ ) the Pierce's elliptic cross section has been used, whereas for the black PET weft yarns (denoted by $P E T_{\text {weft_b}}$ ) the circular cross section has been kept due to their rigidity. The dimensions of the cross section of each type of dielectric thread used in the proposed antenna are indicated in Table III.

According to the procedure referenced in Section II, the proportion of air in the multifilaments can be calculated, as summarised in Table IV.

According to the same procedure, the design of the woven structure is required. Due to the fact that the cross section

TABLE III

Dimensions of the Cross Sections of the Dielectric Materials

\begin{tabular}{ccccc}
\hline \multirow{2}{*}{ Thread } & $\begin{array}{c}\text { Thread } \\
\text { direction }\end{array}$ & $\begin{array}{c}\text { Cross } \\
\text { section }\end{array}$ & Dimension & $\begin{array}{c}\text { Value } \\
(\mathrm{mm})\end{array}$ \\
\hline \hline$P E S_{\text {warp }}$ & Warp & Circular & Radius & 0.0125 \\
\hline \multirow{2}{*}{$P E T_{\text {weft_w }}$} & \multirow{2}{*}{ Weft } & Pierce & Horizontal semi-axis & 0.1 \\
\cline { 4 - 5 } & & & Vertical semi-axis & 0.03 \\
\hline$P E T_{\text {weft_b }}$ & Weft & Circular & Radius & 0.46 \\
\hline
\end{tabular}

TABLE IV

Parameters of the EQuivalent Monofilaments

\begin{tabular}{lcc}
\hline Monofilament & Percentage of air & Relative Permittivity \\
\hline \hline$P E S_{\text {warp }}$ & $76 \%$ & $\varepsilon_{\text {mon_PESwarp }}=1.72$ \\
\hline$P E T_{\text {weft_w }}$ & $85 \%$ & $\varepsilon_{\text {mon_PETweft_w }}=2.83$ \\
\hline$P E T_{\text {weft_b }}$ & $70 \%$ & $\varepsilon_{\text {mon_PETweft_b }}=2.11$ \\
\hline
\end{tabular}

TABLE V

DimENSIONS OF THE RADIATING SLOT.

\begin{tabular}{cccccc}
\hline$a_{1}(\mathrm{~mm})$ & $a_{2}(\mathrm{~mm})$ & $a_{3}(\mathrm{~mm})$ & $b_{1}(\mathrm{~mm})$ & $b_{2}(\mathrm{~mm})$ & $b_{3}(\mathrm{~mm})$ \\
\hline \hline 7 & 5 & 2 & 3 & 3 & 0.5 \\
\hline
\end{tabular}

of the PET $T_{\text {weft_b }}$ is much bigger than the others, the weft threads will remain straight, whereas the warp threads will conform the woven structure around the weft threads. As $P E T_{\text {weft_b }}$ yarns are much thicker than the other dielectric threads, the variation in the size of the air gaps between the threads mainly depends on the epi parameter associated to the $P E T_{\text {weft_b }}$ yarns. This epi parameter is equal to 24 ends per inch or, equivalently, there is a $1.1 \mathrm{~mm}$ distance between centres of $P E T_{\text {weft_b }}$ yarns. Although the MM represents an anisotropic structure, this woven density leads to a scalar equivalent relative permittivity of the structure of $\varepsilon_{\mathrm{eq}}=1.1$. This is due to the single polarisation of the antenna and the fact that the current is mostly in the same direction as the propagation direction of the waveguide used in the modelling.

\section{Design of the Antenna}

\section{A. Description of the Antenna}

A fully textile-integrated microstrip-fed slot antenna using rigid weft threads is proposed to work at $5.9 \mathrm{GHz}$. The antenna is based on a microstrip line with a shorted port. The ground plane contains the radiating slot whose centre is placed at a distance, $d_{\mathrm{p}}=16.2 \mathrm{~mm}$, from the short circuit in order to constructively add the incident and the reflected waves in the microstrip line, leading to a maximum of the magnitude of the electrical field in this position, as depicted in Fig. 4a. The antenna is composed of three different layers as shown in Fig. $4 \mathrm{~b}$.

The dimensions of the antenna are the width, $W_{\mathrm{a}}=50 \mathrm{~mm}$, the length, $L_{\mathrm{a}}=50 \mathrm{~mm}$, the substrate height, $H_{\mathrm{ML}}=0.97$ $\mathrm{mm}$ (which is imposed by the employed dielectric threads) and the width of the microstrip line $W_{\mathrm{ML}}=3.5 \mathrm{~mm}$ (which is essentially calculated from the values of $H_{\mathrm{ML}}$ and $\varepsilon_{\mathrm{eq}}$ ). The radiating slot has been optimised for bandwidth enhancement compared to a rectangular-shaped slot. Its dimensions are represented in the magnification of Fig. 4a and detailed in Table V.

\section{B. Translation Into a Woven Prototype}

The ground plane layer is composed of conductive threads in the weft direction $(S h x 2 p)$ and dielectric threads in the warp direction $\left(P E S_{\text {warp }}\right)$. The substrate layer is composed of dielectric threads in both directions ( $P E T_{\text {weft_w }}$ and $P E S_{\text {warp }}$ ) and the microstrip line layer is composed of conductive weft threads $(S h x 2 p)$, dielectric weft threads $\left(P E T_{\text {weft_w }}\right)$ and dielectric warp threads ( $\left.P E S_{\text {warp }}\right)$. A single conductive warp thread $(S h x l p)$ has been used to connect the ground plane layer with the microstrip line layer to achieve the short-circuit.

Due to the fact that all the weft threads in the design have a Pierce's cross section or circular-shaped cross section, these 


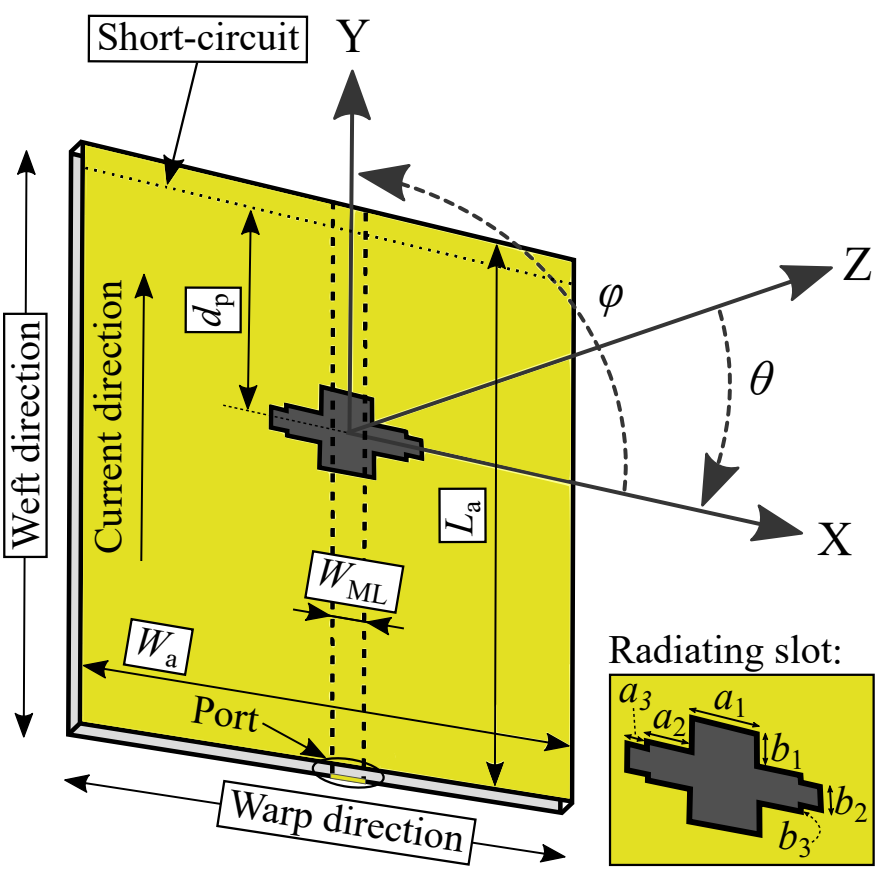

(a)

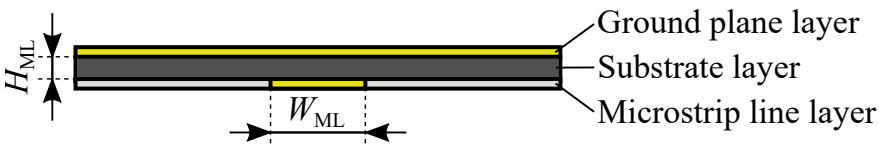

(b)

Fig. 4. Schematic design of the proposed antenna. (a) General overview, reference coordinates system, dimensions and detail of the radiating slot (b) Side view from the port plane, dimensions of the microstrip line and identification of the layers.

sections have been modelled as ellipses (or turned into circunferences). As the weft threads, aligned in the propagation direction, have been found to be rigid threads, different warp patterns have been designed to create the microstrip antenna structure while connecting the different layers of the prototype. For this reason, the paths of the warp threads have been found to be mathematically modelled as ellipse arcs and tangent lines. The proposed woven structure for the MM is depicted in detail in Fig. 5. A side view magnification of the proposed antenna design, as seen from the port plane, is shown in Fig. $5 \mathrm{a}$, where the weft ends and the warp threads are represented. Figure $5 \mathrm{~b}$ depicts the bottom view and a magnification, where the microstrip line can be seen.

\section{Simulated Results}

The proposed design has been analysed using a 3D high frequency electromagnetic simulator with a Transient Solver. Fig. 6 depicts the simulated magnitude of the reflection coefficient (dB) and bandwidth (shaded) of the LM. Figure 7 shows the definition of the $E$-plane and the $H$-plane of the proposed antenna, whereas Fig. 8 represents the simulated normalised radiation patterns: $E$-plane and $H$-plane co-polar contributions.

The simulated values of the gain, directivity and radiation efficiency are $G_{\mathrm{S}}=-1.5 \mathrm{~dB}, D_{\mathrm{S}}=5.1 \mathrm{~dB}$ and $\varepsilon_{\text {eff_S }}=$
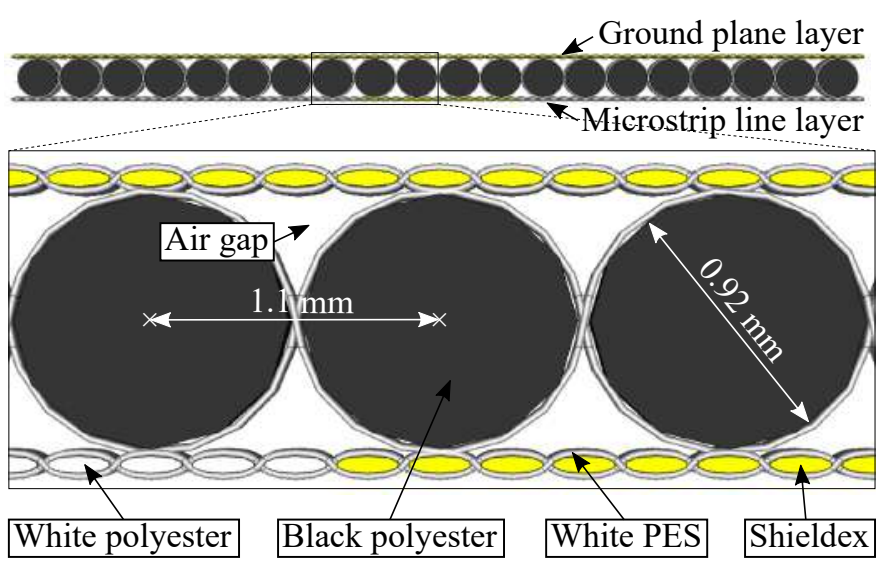

(a)

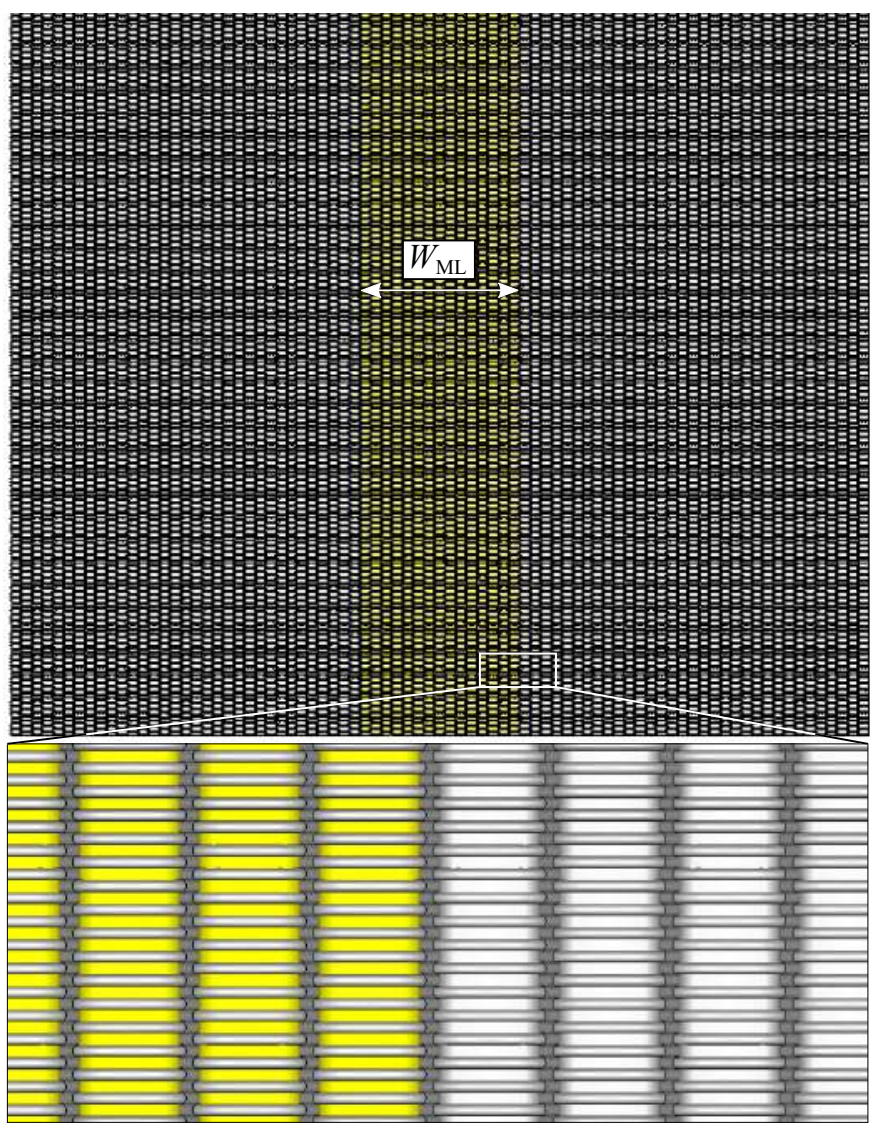

(b)

Fig. 5. Schematic simulated monofilament model of the microstrip geometry. (a) Side view from the port plane, magnification and materials. (b) Bottom view and magnification.

$22 \%$, respectively. The negative value of the simulated gain is, essentially, due to the low value of the equivalent conductivity $\sigma_{\mathrm{eq}}$.

\section{FABRICATION PROCESS}

A fully textile-integrated antenna has been manufactured, as depicted in Fig. 9, using two processes. First, an industrial loom has been used to fabricate the textile structure and, secondly, a prototyping laser machine has been employed to create the radiating slot. Finally, an SMA connector is mounted on the woven antenna. 


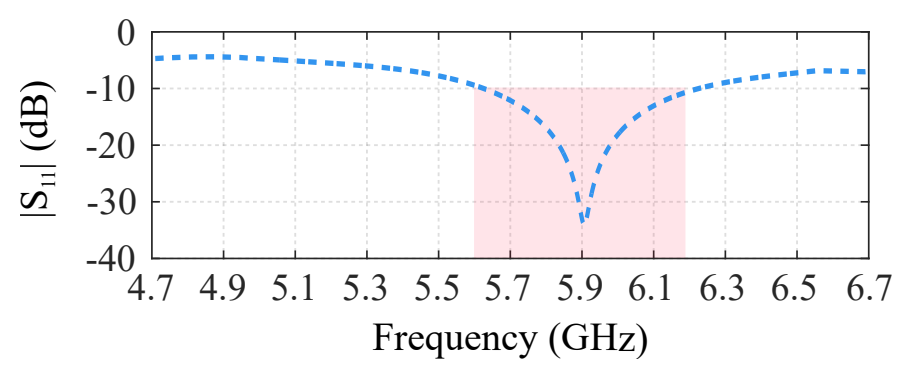

Fig. 6. Simulated magnitude of the reflection coefficient $(\mathrm{dB})$ and bandwidth (shaded).

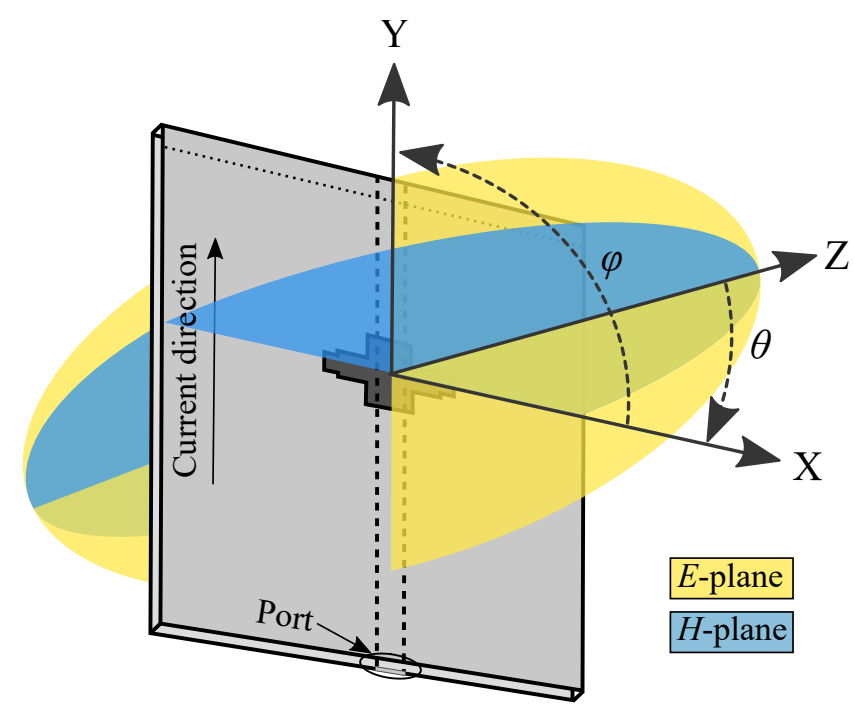

Fig. 7. Definition of the $E$-plane and the $H$-plane.

\section{A. Textile Short-Circuited Microstrip Line Fabrication}

An industrial MüGrip loom with a maximum density of 107 epi has been used for the manufacturing of the textile structure. First, the three layers of warp threads are assembled in the loom, except in the position corresponding to the short-circuit, where only one conductive thread is required to connect all the layers. Then, the weft yarns are successively inserted in the woven structure during the fabrication process. A finishing process is needed after removing the fabric from the loom in order to achieve the requirements, by the use of a stenter machine. Fig. 9a shows the top view of the antenna (slotted ground plane layer), whereas Fig. 9b represents the bottom view of the antenna (microstrip line layer). In Fig. 9c a side view from the port plane is shown, where the three layers of the prototype can be seen. Fig. 9d shows a detailed view of the microstrip line and the conductive thread implementing the short-circuit.

\section{B. Radiating Slot Fabrication}

A laser prototyping machine LPKF ProtoLaser has been used to structure the radiating slot in the ground plane layer of the prototype. The power level has been adjusted to structure only the ground plane layer of the antenna, avoiding the modification of the middle layer. Fig. 10a represents the laser patterned slot, together with a magnification of the cut. Fig.

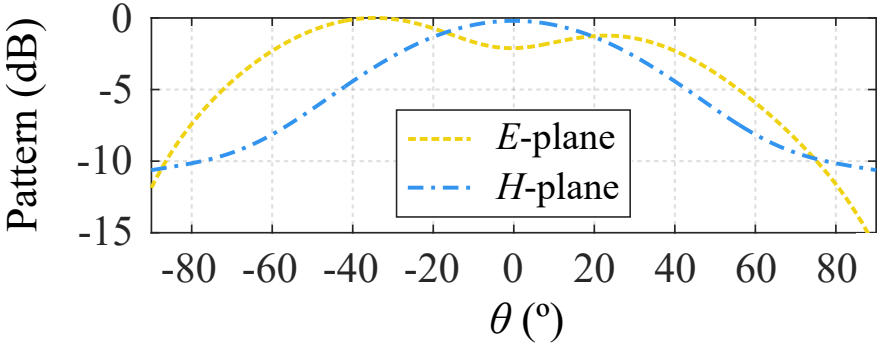

Fig. 8. Simulated normalised radiation patterns: $E$-plane and $H$-plane copolar contributions.

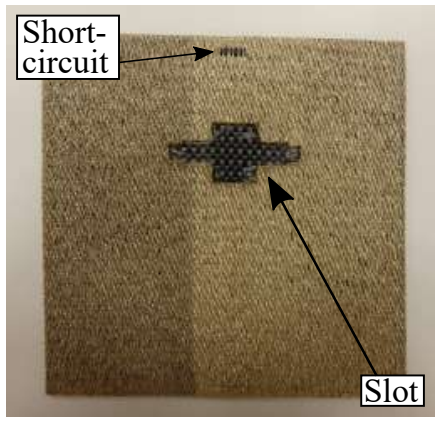

(a)

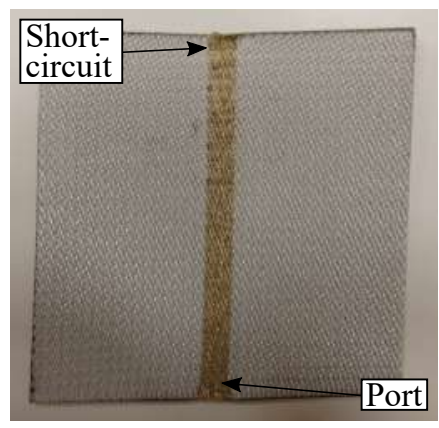

(b)

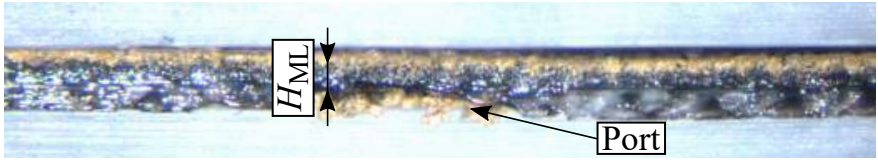

(c)

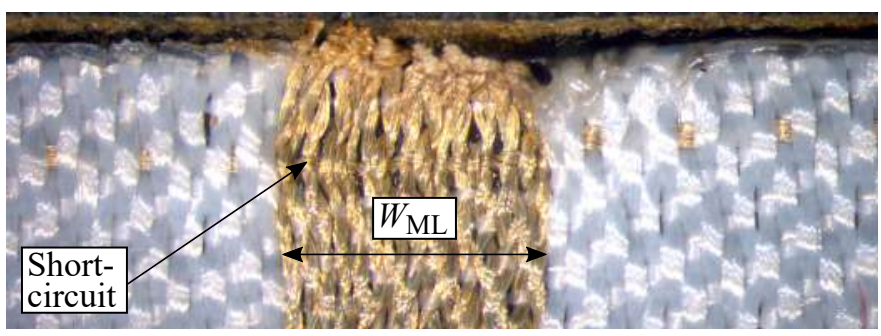

(d)

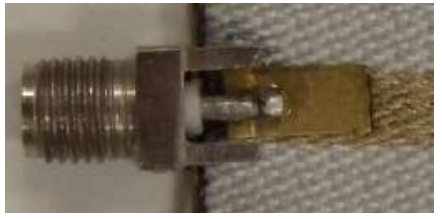

(e)

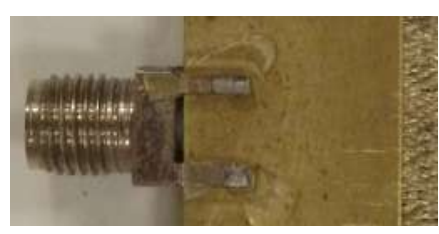

(f)
Fig. 9. Manufactured textile prototype without connector. (a) Top view. (b) Bottom view. (c) Side view from the port plane. (d) Microstrip line and shortcircuit detail. (e) Connector view (microstrip line layer). (f) Connector detailed view (ground plane layer).

$10 \mathrm{~b}$ shows the radiating slot after removing the leftover textile material: only the ground plane layer of the prototype has been cut even though the three layers remain connected through yarns.

\section{Connectorisation of the Antenna}

An SMA connector has been installed in the woven prototype. Two shims of brass have been cut to size and placed on 

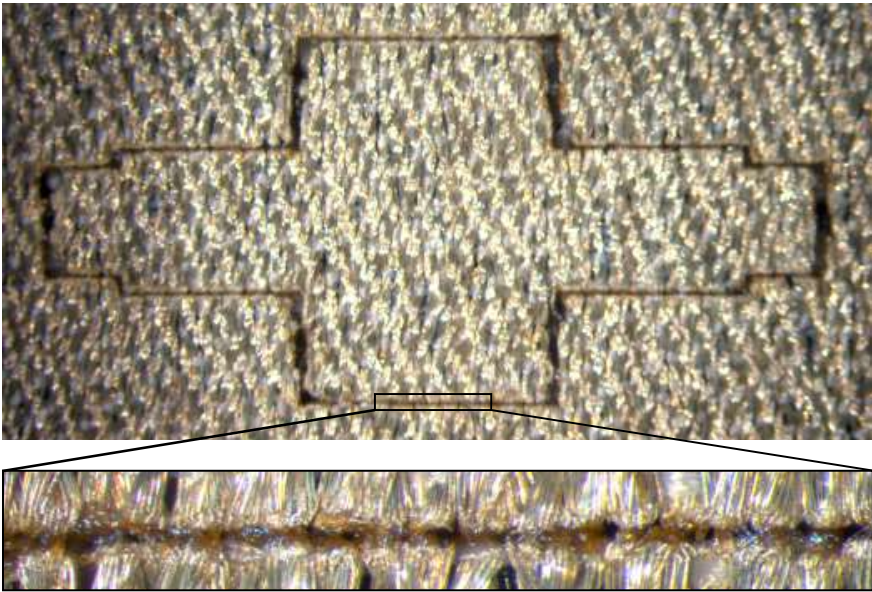

(a)

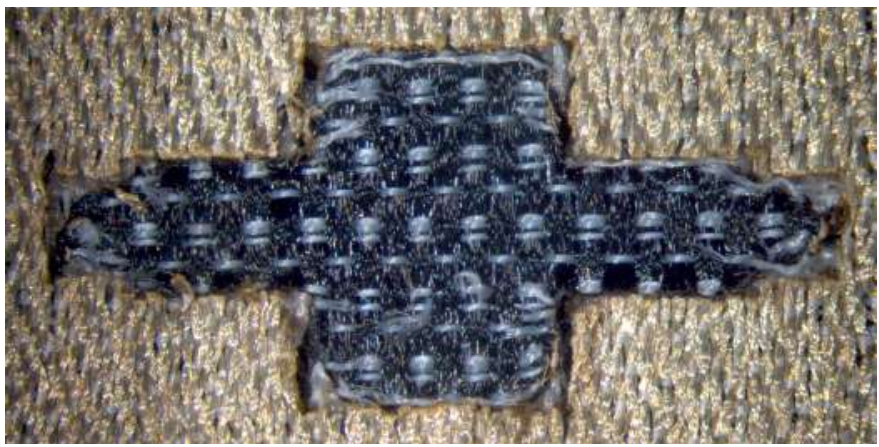

(b)

Fig. 10. Detailed manufacturing process of the textile slot. (a) Before removing the leftover textile material and magnification of a cut area. (b) After removing the leftover textile material.

top of the microstrip line and under the ground plane, in order to provide the fabric with the necessary rigidity to install the connector as shown in Fig. 9e and Fig. 9f. The connector has been secured to the brass shims using conductive epoxy glue.

\section{EXPERIMENTAL VALIDATION}

In order to experimentally validate the prototype, the reflection coefficient has been measured using an Agilent N5247A PNA-X vector network analyzer and compared with the simulations, as shown in Fig. 11. The measured bandwith has been found to be equal to $9.3 \%$.

The prototype has been measured at the spherical range in anechoic chamber of the University of Oviedo to characterise its radiation pattern, directivity, gain, and radiation efficiency. Measurements have been conducted at the frequency $f_{\mathrm{o}}=5.9$ $\mathrm{GHz}$, which corresponds to the $\left|S_{11}\right|$ minimum (as observed in Fig. 11).

The radiation pattern of the textile antenna under test (AUT) has been measured at the distance of $R=5.4 \mathrm{~m}$, which is in the far field (FF) region. A picture of the measurement set-up at the spherical range in anechoic chamber is shown in Fig. 12, where the AUT has been mounted in a foam platform and the probe antenna is a Narda 642 Standard Gain Horn (SGH) [23]. The $E$-plane and $H$-plane normalised radiation patterns of the AUT have been measured and compared with the

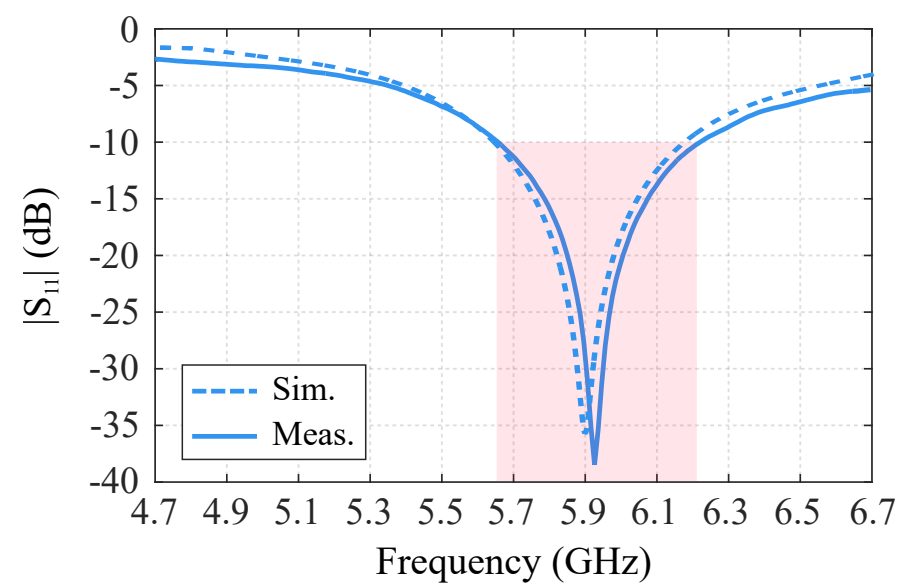

Fig. 11. Simulated and measured magnitude of the reflection coefficient $(\mathrm{dB})$ and bandwidth (shaded).

simulated data, as depicted in Fig. 13 and Fig. 14, respectively. A good agreement between simulated and measured co-polar components can be noticed (cross-polar component is below $-40 \mathrm{~dB}$ in simulations).

Directivity has been calculated by integrating the measured AUT radiation pattern, yielding $D_{\mathrm{M}}=4.9 \mathrm{~dB}$, which is in agreement with the low directivity of the AUT radiation pattern (as confirmed by the directive gain pattern depicted in Fig. 15). This result is of great interest for automotive DSRC antennas, where antennas with low directivity are preferred [24], [25].

AUT gain has been evaluated by means of the wellknown inter-comparison technique [26], resulting in $G_{\mathrm{M}}=$ $-2.75 \mathrm{~dB}$. Finally, given the AUT gain and directivity, the AUT radiation efficiency can be calculated: $\varepsilon_{\text {eff_M }}=100 \times$ $10^{\left(G_{\mathrm{M}}-D_{\mathrm{M}}\right) / 10}=17.2 \%$. A comparative between the simulated and the measured values of the gain, directivity and radiation efficience is depicted in Table VI. The low values of both gains can be justified due to the ohmic losses of the textile antenna conductive fibers. Moreover, the difference between the simulated and the measured gain values can be justified due to manufacturing errores in the connection between the textile antenna and the RF connector and the silver plated coating deterioration due to the wear out, which could be solved by the use of non-coated stainless steel threads instead.

A comparative between different microstrip textile antennas found in the literature has been summarised in Table VII in terms of operating frequency, $f$, bandwidth, $B W$, gain, $G$, directivity, $D$, and radiation efficiency, $\varepsilon_{\text {eff }}$. In the case a parameter has not been provided in the corresponding paper, NP has been indicated instead. The antennas described in [12], [27], [28] present higher radiation efficiencies, due to different reasons. First, their operating frequencies are lower, consequently, the losses are also lower, leading to higher efficiencies. Moreover, the different techniques used to provide the textile antennas with the conductive elements, inkjet-printing, copper patches and copper plated nylon fabrics, respectively, do not allow a fully textile integration while avoiding subsequent posttreatments.

The antennas described in [29], [30] present higher gains, 


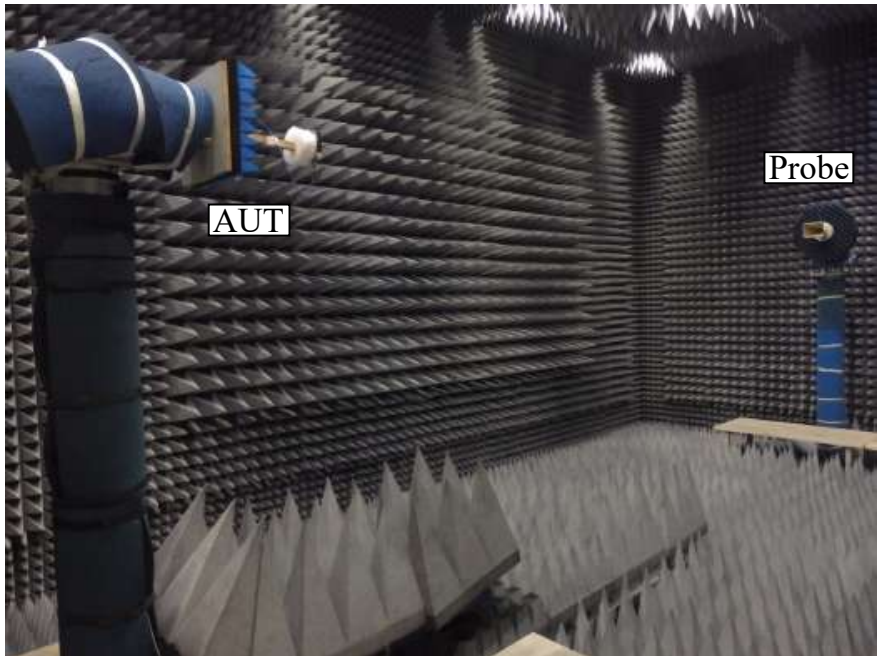

(a)

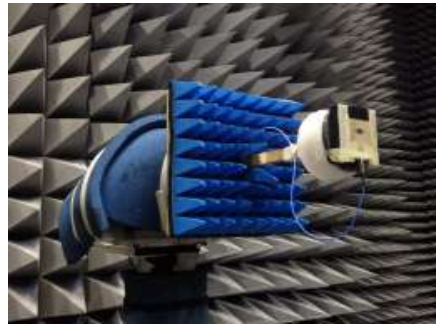

(b)

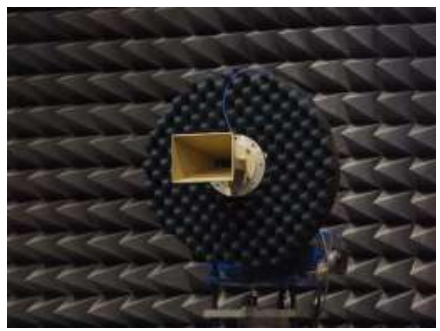

(c)
Fig. 12. Measurement set-up in anechoic chamber. (a) Overview of the setup. (b) Detailed antenna under test (AUT). (c) Detailed probe antenna.

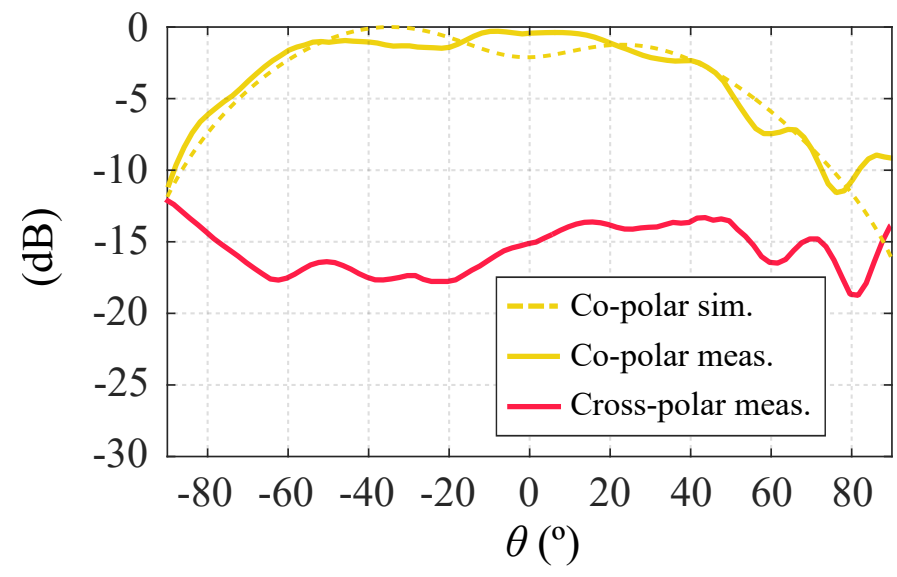

Fig. 13. Simulated and measured $E$-plane normalised radiation pattern $(\mathrm{dB})$.

although information regarding the radiation efficiency is not provided for comparative. The antennas presented in [31], [32] provide information regarding their radiation efficiencies and is comparable to radiation afficiency achieved in this work, although the conductive elements of the mentioned antennas are achieved by the use of copper patches and silver coated nylon fabric, respectively, leading to less textile integrated prototypes.

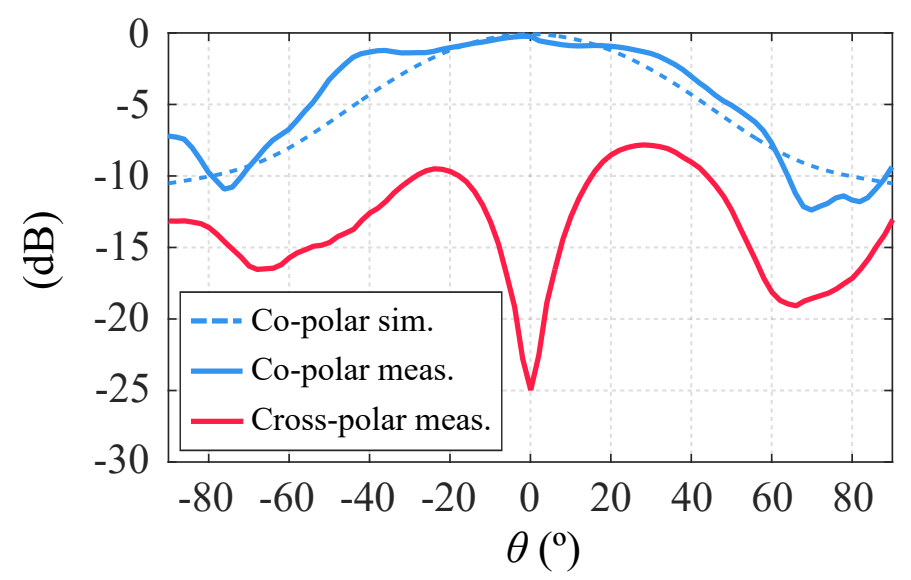

Fig. 14. Simulated and measured $H$-plane normalised radiation pattern $(\mathrm{dB})$.

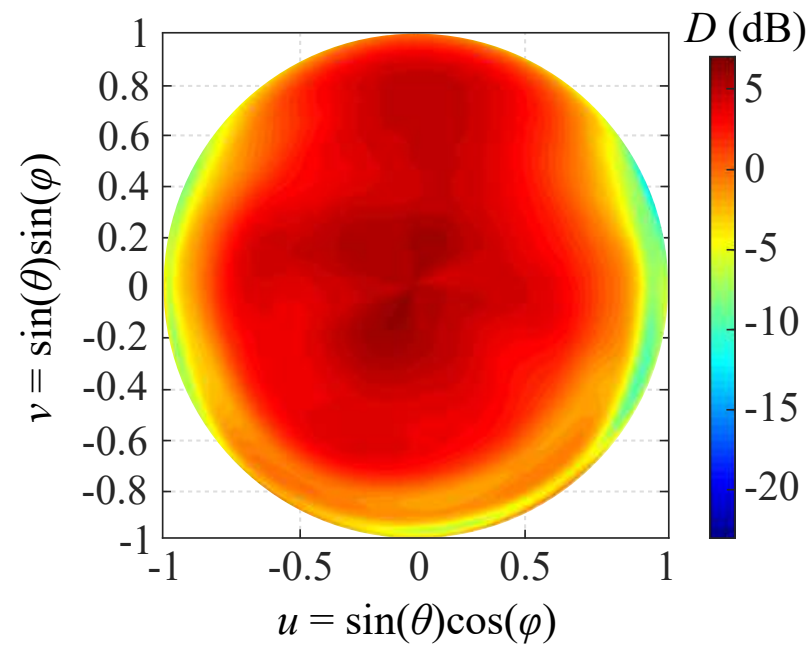

Fig. 15. Directive gain pattern of the AUT. Directive gain at $\theta=0^{\circ}, \phi=0^{\circ}$ is $3.7 \mathrm{~dB}$. Directivity $D=4.9 \mathrm{~dB}$ (at $\theta=8^{\circ}, \phi=243^{\circ}$ ).

\section{CONCLUSiON}

A novel fully textile-integrated microstrip-fed slot antenna for its use in DSRC for automobile upholsteries has been presented. First, a complete charaterisation of the employed materials has been presented. Then, a parametric modelling technique to simulate textile structures based on the reduction of the computational complexity of the problem has been discussed. To validate the modelling technique, a prototype has been manufactured and experimentally characterised. A good agreement between simulations and measurements has been achieved, consequently the theoretically predicted behaviour of the textile structure. Nevertheless, in order to improve the measured gain of the antenna it is proposed to use conductive

TABLE VI

Comparative Between Simulations and Measurements.

\begin{tabular}{cccc}
\hline Parameter & Gain $(\mathrm{dB})$ & Directivity $(\mathrm{dB})$ & Radiation efficiency \\
\hline \hline Simulated & -1.5 & 5.1 & $22 \%$ \\
\hline Measured & -2.75 & 4.9 & $17.2 \%$ \\
\hline
\end{tabular}


TABLE VII

Comparative Between Textile Antennas in The Literature.

\begin{tabular}{cccccc}
\hline Reference & $f(\mathrm{GHz})$ & $B W(\%)$ & $G(\mathrm{~dB})$ & $D(\mathrm{~dB})$ & $\varepsilon_{\text {eff }}(\%)$ \\
\hline \hline$[12]$ & 0.43 & 5.2 & 2.41 & $\mathrm{NP}$ & 51 \\
\hline$[27]$ & 2.505 & $\mathrm{NP}$ & 5.98 & 8.72 & 53 \\
\hline$[28]$ & 2.45 & 6.04 & 9.1 & $\mathrm{NP}$ & 63 \\
\hline$[29]$ & 5.5 & 1.6 & 3.5 & $\mathrm{NP}$ & $\mathrm{NP}$ \\
\hline$[30]$ & 6.0 & 9.3 & $6.11-6.69$ & $\mathrm{NP}$ & $\mathrm{NP}$ \\
\hline$[31]$ & 1.57542 & 3 & 1.2 & $\mathrm{NP}$ & 19 \\
\hline$[32]$ & 4.725 & $\mathrm{NP}$ & 7.62 & $\mathrm{NP}$ & 38.9 \\
& 5.800 & $\mathrm{NP}$ & 6.73 & $\mathrm{NP}$ & 13.8 \\
\hline This work & 5.9 & 9.3 & -2.75 & 4.9 & 17.2 \\
\hline
\end{tabular}

threads with a lower resistance and to use an electrically conductive epoxy with higher conductivity.

The manufactured prototype reveals the potential of the woven technology applied to microstrip designs working at microwave frequencies, opening a new field of research. This prototype represents a first step in TIC technology and demostrates the possibility of fully integration of antennas in woven structures.

\section{REFERENCES}

[1] G. Ginestet et al., "Embroidered Antenna-Microchip Interconnections and Contour Antennas in Passive UHF RFID Textile Tags", IEEE Antennas Wireless Propag. Lett., vol. 16, pp. 1205-1208, Nov. 2017.

[2] A. Paraskevopoulos et al., "Higher-mode textile patch antenna with embroidered vias for on-body communication", IET Microw. Antennas and Propag., vol. 10, no. 7, pp. 802-807, May 2016.

[3] A. Kiourti, C. Lee and J. L. Volakis, "Fabrication of Textile Antennas and Circuits With $0.1 \mathrm{~mm}$ Precision", IEEE Antennas Wireless Propag. Lett., vol. 15, pp. 151-153, May 2016.

[4] Z. Wang, L. Zhang, Y. Bayram and J. L. Volakis, "Embroidered Conductive Fibers on Polymer Composite for Conformal Antennas", IEEE Trans. Antennas Propag., vol. 60, no. 9, pp. 4141-4147, Sept. 2012.

[5] T. Acti et al., "Embroidered Wire Dipole Antennas Using Novel Copper Yarns", IEEE Antennas Wireless Propag. Lett., vol. 14, pp. 638-641, Nov. 2015.

[6] Y. Senbokuya and H. Tsunoda, "A study on the circular patch antennas using conductive non-woven fiber fabrics", presented at IEEE Antennas Propag. Soc. Int. Symp., San Antonio, TX, USA, June 16-21, 2002.

[7] G. Monti, L. Corchia, E. De Benedetto and L. Tarricone, "Wearable logo-antenna for GPS-GSM-based tracking systems", IET Microw. Antennas and Propag., vol. 10, no. 12, pp. 1332-1338, Sept. 2016.

[8] R. K. Shawl, B. R. Longj, D. H. Werner and A. Gavrin, "The Characterization of Conductive Textile Materials Intended for Radio Frequency Applications", IEEE Antennas Propag. Mag., vol. 49, no. 3, pp. 28-40, June 2007.

[9] Xiaoyou Lin, B. C. Seet and F. Joseph, "Fabric antenna with body temperature sensing for BAN applications over 5G wireless systems", presented at the Int. Conf. on Sensing Technol., Auckland, New Zealand, Dec. 8-10, 2015.

[10] R. Yahya, M. R. Kamarudin, N. Seman and H. U. Iddi, "Eye shaped fabric antenna for UWB application", presented at the IEEE Antennas Propag. Soc. Int. Symp., Orlando, FL, July 7-13, 2013.
[11] H. A. Elmobarak Elobaid, S. K. Abdul Rahim, M. Himdi, X. Castel and M. Abedian Kasgari, "A Transparent and Flexible Polymer-Fabric Tissue UWB Antenna for Future Wireless Networks", IEEE Antennas Wireless Propag. Lett., vol. 16, pp. 1333-1336, Dec. 2016.

[12] W. G. Whittow et al., "Inkjet-Printed Microstrip Patch Antennas Realized on Textile for Wearable Applications", IEEE Antennas Wireless Propag. Lett., vol. 13, pp. 71-74, Jan. 2014.

[13] A. Chauraya et al., "Inkjet printed dipole antennas on textiles for wearable communications", IET Microw. Antennas and Propag., vol. 7, no. 9, pp. 760-767, June 2013.

[14] M. L. Scarpello, I. Kazani, C. Hertleer, H. Rogier and D. Vande Ginste, "Stability and Efficiency of Screen-Printed Wearable and Washable Antennas", IEEE Antennas Wireless Propag. Lett., vol. 11, pp. 838-841, July 2012.

[15] M. Akbari, L. Sydänheimo, Y. Rahmat-Sami, J. Virkki and L. Ukkonen, "Implementation and performance evaluation of graphene-based passive UHF RFID textile tags", presented at the Int. Symp. Electromagnetic Theory, Espoo, Finland, Aug. 14-18, 2016.

[16] R. Moro, S. Agneessens, H. Rogier, A. Dierck and M. Bozzi, "Textile Microwave Components in Substrate Integrated Waveguide Technology", IEEE Trans. Microw. Theory Techn. , vol. 63, no. 2, pp. 422-432, Feb. 2015.

[17] F. X. Liu, Z. Xu, D. C. Ranasinghe and C. Fumeaux, "Textile Folded Half-Mode Substrate-Integrated Cavity Antenna", IEEE Antennas Wireless Propag. Lett., vol. 15, pp. 1693-1697, Feb. 2016.

[18] L. Alonso-González et al., "Novel parametric electromagnetic modelling to simulate Textile Integrated Circuits", presented at the Int. Conf. Numerical Electromagnetic and Multiphysics Modeling and Optimization for RF, Microwave, and Terahertz Applications, Seville, Spain, May 17 19, 2017.

[19] L. Alonso-González et al., "On the techniques to develop millimeterwave textile integrated waveguides using rigid warp threads", in IEEE Trans. Microw. Theory Techn., vol. PP, no. 99, pp. 1-11.

[20] H. U. Jinlian, "Structure and mechnics of woven fabrics", in Woodhead Publishing in Textiles, The Textile Institute, New York, NY, USA, 2004, pp. 63-66.

[21] L. Chao, B. Yu, A. Sharma and M. N. Afsar, "Dielectric permittivity measurements of thin films at microwave and terahertz frequencies", presented at the European Microwave Conf., Manchester, UK, Oct. 1013, 2011.

[22] B. C. Steele, "Electronic ceramics", in Elsevier Applied Science, London, UK, USA, 1991, pp. 140.

[23] Narda. 642 model Standard Gain Horn, datasheet [accessed September 7 , 2017]. Available at: https://nardamiteq.com/docs/WAVEGUIDEHORN ANTENNAS_STANDARD_GAIN_HORNS_2.60_TO_40_GHZ.PDF

[24] A. Malarky, G. Z. Rafi, S. Safavi-Naeini and L. Delgrossi, "A Planar Dual Band GPS and DSRC Antenna for Road Vehicles", presented at the IEEE 66th Vehicular Technol. Conf., Baltimore, MD, 2007, pp. 20962100.

[25] C. Y. Liou, S. G. Mao, T. C. Chiang and C. T. Tsai, "Compact and low-profile conical antenna for automotive DSRC application", IEEE Int. Symp. on Antennas and Propag. (APSURSI), Fajardo, Puerto Rico, 2016, pp. 117-118.

[26] IEEE Standard test procedures for antennas, ANSI/IEEE Std 149-1979.

[27] H. Wang, Z. Zhang, Y. Li and Z. Feng, "A dual-resonant shorted patch antenna for wearable application in $430 \mathrm{MHz}$ band," IEEE Trans. Antennas Propag., vol. 61, no. 12, pp. 6195-6200, Dec. 2013.

[28] C. Hertleer et al., "Aperture-coupled patch antenna for integration into wearable textile systems," IEEE Antennas Wireless Propag. Lett., vol. 6, pp. 392-395, 2007

[29] S. Ha, S. Lee, H. J. Yoo and C. Jung, "Compact textile patch antenna for wearable fabric applications," presented in Asia-Pacific Microwave Conf., Yokohama, Japan, Dec. 7-10, 2010.

[30] S. J. Ha and C. W. Jung, "Reconfigurable beam steering using a microstrip patch antenna with a U-slot for wearable fabric applications," IEEE Antennas Wireless Propag. Lett., vol. 10, pp. 1228-1231, 2011.

[31] I. Gil and R. Fernández-García, "Wearable GPS patch antenna on jeans fabric," presented in Progress in Electromagnetic Research Symp. (PIERS), Shanghai, China, Aug. 8-11, 2016.

[32] S. J. Chen, T. Kaufmann and C. Fumeaux, "Wearable textile microstrip patch antenna for multiple ISM band communications," presented in IEEE Int. Symp. on Antennas and Propag. (APSURSI), Orlando, FL, July $7-13,2013$. 


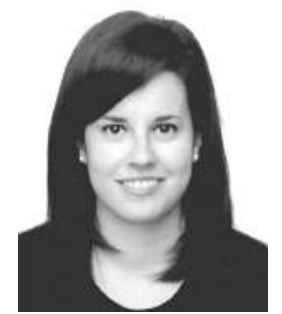

in textile technology.
Leticia Alonso-González (S'14) received the M.Sc. degree in telecommunications engineering from the University of Oviedo, Gijón, Spain, in 2014 and she is currently working toward the Ph.D. degree at the University of Oviedo.

Since 2014, she has been working as a researcher in the Signal Theory and Communications Group University of Oviedo. Her main research effort is focused on the design, simulation and manufacturing techniques to develop microwave and millimetrewave passive circuits and antennas fully integrated

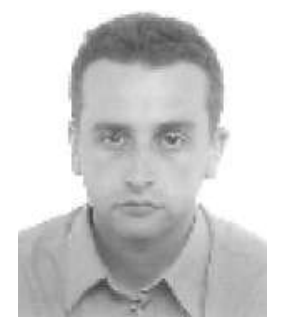

Samuel Ver-Hoeye (M'05) received the M.Sc. degree in electronic engineering from the University of Gent, Gent, Belgium, in 1999, and the Ph.D. degree from the University of Cantabria, Santander, Spain, in 2002 .

$\mathrm{He}$ is currently an Associate Professor with the Department of Electrical and Electronic Engineering, University of Oviedo, Gijón, Spain. His main research interests are focused on the design and analysis of nonlinear oscillator based circuits, millimeter wave and terahertz antennas, circuits and systems, graphene based components, and textile integrated circuits and antennas.

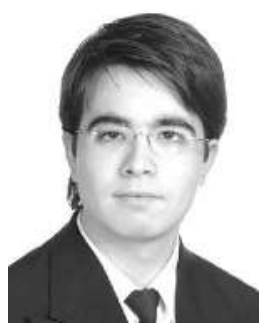

Carlos Vázquez-Antuña received the M.Sc. degree in telecommunication engineering, M.Sc. degree in information technology and mobile communications, and $\mathrm{Ph} . \mathrm{D}$. degree from the University of Oviedo, Gijón, Spain, in 2007, 2008, and 2013, respectively.

From 2007 to 2012, he was a Graduate Research Assistant, and since 2012, a Research Fellow with the Signal Theory and Communications Group, University of Oviedo. His research efforts mainly focus on nonlinear analysis and optimization techniques for the design of multifunctional oscillator-based circuits, active antennas and passive components, such as frequency multipliers and harmonic mixers, at microwave, millimeter/submillimeter-wave, and terahertz frequencies.

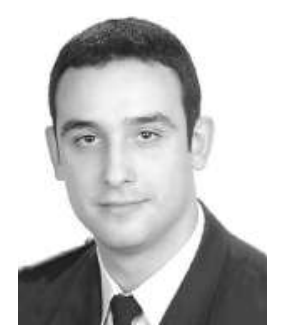

Miguel Fernández-García received the M.Sc. degree in telecommunication engineering, the M.Sc. degree in information technology and mobile communications and the Ph.D. degree from the University of Oviedo, Gijón, Spain, in 2006, 2010, and 2010, respectively.

From 2006 to 2008, he was a Research Fellow with the Signal Theory and Communications Group, University of Oviedo, where he has been an Associate Professor since 2008. His current research interests include nonlinear analysis and optimization techniques for the design of oscillator-based circuits, active antennas and frequency multipliers and mixers at the microwave, millimeter/submillimeterwave, and terahertz frequency bands.

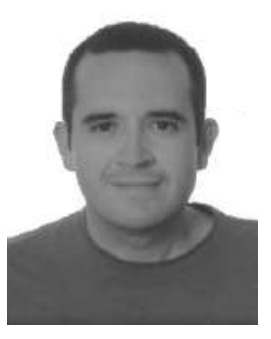

Yuri Álvarez-López (S'06-M’09-SM'15) received the M.S. and Ph.D. degrees in telecommunication engineering in 2006 and 2009, respectively. He was a Visiting Scholar in the Department of Electrical Engineering and Computer Science, Syracuse University, Syracuse, NY, USA, in 2006 and 2008, and a Visiting Postdoc at the Gordon Center for Subsurface Sensing and Imaging Systems (CenSSIS)ALERT Center of Excellence, Northeastern University, Boston, MA, USA, in 2011, 2012, and 2013. $\mathrm{He}$ is currently an Assistant Professor at the Signal Theory and Communications of the University of Oviedo, Gijón, Spain. His interests and research studies have been focused on antenna diagnostics, antenna measurement techniques, RF techniques for indoor location, and inverse scattering and imaging techniques.Dr. Alvarez received the 2011 Regional and National Awards to the Best Ph.D. Thesis on Telecommunication Engineering (category: security and defense).

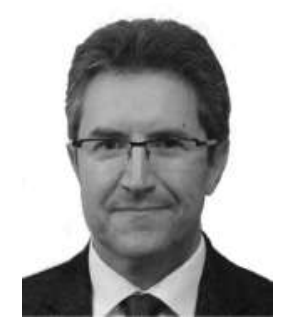

Fernando Las-Heras Andrés (M'86-SM'08) received the M.S. and Ph.D. degrees in telecommunication engineering from the Technical University of Madrid (UPM), Madrid, Spain, in 1987 and 1990, respectively.

He was a National Graduate Research Fellow from 1988 to 1990 and an Associate Professor from 1991 to 2000 with the Department of Signal, Systems and Radiocom, UPM. He was the Vice-Dean of Telecommunication Engineering with the Technical School of Engineering, Gijón, from 2004 to 2008. He was a Visiting Researcher with Syracuse University, New York, NY, USA and a Visiting Lecturer with the National University of Engineering, Lima, Peru, and the École Supérieure d'Ingénieurs en Génie Électrique, Rouen, France. He has been the Head with the Signal Theory and Communications Research Group, Department of Electrical Engineering, University of Oviedo, Gijón, Spain, since 2001, and has been a Full Professor since 2003. He has authored over 450 technical journal and conference papers in the areas of electromagnetic radiation, propagation and scattering theory and applications as well as inverse problems.

Dr. Las-Heras held the Telefónica Chair on "RF Technologies, ICTs Applied to Environment and Climate Change", and ICTs and Smartcities," from 2005 to 2015. He was a member of the Board of Directors of the IEEE Spain Section from 2012 to 2015, and a member of the Science, Technology and Innovation Council of Asturias, Spain, in 2010. He is a member of the IEEE Microwaves and Antennas Propagation Chapter (AP03/MTT17) Board from 2016 to 2018 